\title{
Prediction of preterm labour by cervical length
}

\section{Urvi Tanna Wadhawan, Neelima P. Shah*, Ajit N. Patil}

Department of Obstetrics and Gynecology, D.Y. Patil Medical College, Kolhapur, Maharashtra, India

Received: 26 April 2017

Accepted: 22 May 2017

\section{*Correspondence:}

Dr. Neelima P. Shah,

E-mail: neelimapshah@gmail.com

Copyright: (c) the author(s), publisher and licensee Medip Academy. This is an open-access article distributed under the terms of the Creative Commons Attribution Non-Commercial License, which permits unrestricted non-commercial use, distribution, and reproduction in any medium, provided the original work is properly cited.

\section{ABSTRACT}

Background: Preterm birth is one of the commonest causes of perinatal mortality. Cervical length is one of the major determinants of preterm delivery.

Methods: This prospective observational study of 100 pregnant women attending ANC OPD was carried out at D.Y. Patil Hospital, Kolhapur. The pregnant women were scanned for cervical length between 11-14 weeks and 20-22 weeks of gestation, using USG machine with TVS probe (mindray DC-7).

Results: The mean value of cervical length in pregnant women at 11-14 weeks was $3.94 \mathrm{~cm}$ and at 20-22 weeks of gestation it was $3.38 \mathrm{~cm}$. There was shortening in the pregnant cervix from first to second trimester. In the study $12 \%$ of patients delivered prematurely who had reduction in cervical length from first trimester to second trimester. The inverse relation between the cervical length during pregnancy and frequency of preterm delivery was confirmed. The decrease in cervical length at 11-14 weeks of gestation and 20-22 weeks of gestation was useful for identifying patients at increased risk for pre-trerm.

Conclusions: Our findings confirm those of previous studies that have found an inverse relation between the length of the cervix, as measured by transvaginal ultrasonography during pregnancy, and the frequency of preterm delivery. We found that the cervical length measured at 11-14 weeks and 20-22 weeks gestation was decreased in asymptomatic women with single to $\mathrm{n}$ pregnancies was useful for identifying patients at increased risk for preterm delivery.

Keywords: Cervical length, Preterm, Pregnancy

\section{INTRODUCTION}

Ultrasound assessment of the cervix, in recent decades, has become an important part of obstetric diagnostic imaging, especially since the development of transvaginal probes and the increasing acceptance by patients of transvaginal sonography during pregnancy. Transvaginal sonographic measurement of the cervix is a reliable alternative method for the assessment of cervical length as it allows better quality and more accurate visualization of the uterine cervix. ${ }^{1}$ Preterm delivery is responsible for nearly $75 \%$ of all neonatal death and neurological handicap. ${ }^{2}$ Preterm labour is defined as onset of labour before 37 weeks of gestation. ${ }^{3}$ But delivery before 34 weeks of gestation has a greater impact on the perinatal morbidity and mortality. Cervical length is one of the major determinants of preterm delivery. The risk of preterm birth varies inversely with cervical length measured by transvaginal/ transabdominal scan 20-22 weeks. ${ }^{4}$ Ultrasound assessment of cervical length has therefore become an important component of obstetric scan.

Several studies have reported that transvaginal cervical length assessment may be a useful tool for prediction of preterm delivery. Some have demonstrated that 
measurement of cervical length at 11-14weeks was useful, whereas others did not find it as a reliable predictor of preterm delivery. ${ }^{5-7}$ Many studies have found that cervical length at 20-22 weeks is a reliable predictor of preterm delivery. ${ }^{8}$ Hence there is a need to evaluate the predictive value of transvaginal cervical length between 11-14 weeks and 20-22 weeks of gestation in preterm labour.

\section{METHODS}

100 women attended the OPD at D. Y. Patil hospital Kolhapur between 11-14 weeks were included in the study. Cervical length was measured using transvaginal ultrasonography with the standard longitudinal view of cervix while patient's bladder was empty. USG machine with TVS probe (Mindrey-DC7) was used to measure cervical length. It was measured by keeping the probe $3 \mathrm{~cm}$ away from the posterior fornix. The cervical length is defined as the length between the internal os and external os. Patient then followed up and cervical length at 20-22weeks of gestation was repeated again during the routine anomaly scan. The patients were then followed up until they deliver.

The variables analysed (i) The mean cervical length at 11-14 weeks and at 20-22weeks. (ii) The rate of shortening of cervical length in those who deliver at term and preterm. (iii) The cervical length at 11-14 weeks and 20-22 weeks was correlated with gestational age at delivery and the predictive value of the same were determined.

\section{Statistical analysis}

The appropriate statistical analysis method was applied based on data analysis. The mean cervical length was calculated at 11-14 weeks and 20-22 weeks scans. Student's ' $t$ ' test was used to determine in the differences in the cervical lengths at the first and second scans for the group of patients who delivered either at term or preterm. Logistic regression analysis was used to determine the independent contribution of shortening of the cervix, the cervical length at the 11-14 week and 20-22 week scans, and the demographic characteristics in predicting preterm delivery in women.

\section{RESULTS}

The Table 1 shows $53 \%$ of women in the study group are in the age group of 21-25 years. Median age was 22 years. Minimum age of the subject studied being 18 years and maximum being 33 years.

Cervical length at 11-14 weeks in majority of the pregnant women studied was between $3.6-4.0 \mathrm{~cm}$ with mean cervical length being $3.94 \mathrm{~cm}$ (Table no.2). Minimum cervical length measured was $3 \mathrm{~cm}$ and maximum $5 \mathrm{~cm}$. Mean $\pm \mathrm{SD}=3.94 \mathrm{~cm} \pm 0.41$, Median $=4$ $\mathrm{cm}$. Cervical length at 20-22 weeks in majority of the pregnant women studied was between $3.1-3.5 \mathrm{~cm}$ with mean cervical length being $3.37 \mathrm{~cm}$ (Table 3). Minimum cervical length measured was $2.2 \mathrm{~cm}$ and maximum $4.5 \mathrm{~cm}$. Mean $\pm \mathrm{SD}=3.37 \mathrm{~cm} \pm 0.48$, Median $=3.4 \mathrm{~cm}$.

Table 1: Patients distribution according to age.

\begin{tabular}{|lll|}
\hline Age in years & No of pregnant women & $\%$ \\
\hline$\leq 20$ & 33 & 33 \\
\hline $21-25$ & 53 & 53 \\
\hline $26-30$ & 13 & 13 \\
\hline $31-35$ & 1 & 1 \\
\hline Total & 100 & 100 \\
\hline
\end{tabular}

Table 2: Patients distribution according to cervical length at 11-14 weeks.

\begin{tabular}{|lll|}
$\begin{array}{l}\text { Cervical length in } \\
\text { cm }\end{array}$ & No. of pregnant women & $\%$ \\
\hline $2.1-2.5$ & 0 & 0 \\
\hline $2.6-3.0$ & 2 & 2 \\
\hline $3.1-3.5$ & 16 & 16 \\
\hline $3.6-4.0$ & 56 & 56 \\
\hline $4.1-4.5$ & 17 & 17 \\
\hline $4.6-5.0$ & 9 & 9 \\
\hline Total & 100 & 100 \\
\hline
\end{tabular}

Table 4 shows $88 \%$ of the subjects studied, had full term 100 women included in the present study were divided in 3 groups according to reduction in cervical length measured with TVS at 11-14weeks and 20-22 weeks.

- Group A-With reduction in cervical length $<0.5 \mathrm{~cm}$.

- Group B-With reduction in cervical length $0.5 \mathrm{~cm}$ $1 \mathrm{~cm}$.

- Group C-With reduction in cervical length $>1 \mathrm{~cm}$.

Table 3: Patients distribution according to cervical length of 20-22 weeks.

\begin{tabular}{|lll|}
\hline Cervical length in cm & $\begin{array}{l}\text { No. of pregnant } \\
\text { women }\end{array}$ & $\%$ \\
\hline $2.1-2.5$ & 7 & 7 \\
\hline $2.6-3.0$ & 25 & 25 \\
\hline $3.1-3.5$ & 39 & 39 \\
\hline $3.6-4.0$ & 20 & 20 \\
\hline $4.1-4.5$ & 9 & 9 \\
\hline $4.6-5.0$ & 0 & 0 \\
\hline Total & 100 & 100 \\
\hline
\end{tabular}

In the present study (Table no.5), $28(28 \%)$ patients had< $0.5 \mathrm{~cm}$ reduction in cervical lengths (Group A), $66(66 \%)$ had reduction in cervicallengthsfrom $0.5-1 \mathrm{~cm}$ (group B) and $6(6 \%)$ had reduction in cervical lengths $>1 \mathrm{~cm}$ (Group C). deliveries, whereas $12 \%$ had preterm deliveries.

Table 6 shows, in group A $(n=28) ; 0(0 \%)$ patient had preterm delivery $(<37$ weeks $)$ and 28 (100\%) were 
delivered at term gestation. In group B $(n=66) ; 2(3 \%)$ patients had early preterm deliveries ( $\leq 34$ weeks); $4(6 \%)$ had late preterm deliveries (>34weeks) and remaining 60 $(91 \%)$ were delivered at term gestation. In group $\mathrm{C}(\mathrm{n}=6)$; $3(50 \%)$ patients had early preterm deliveries $(\leq 34$ weeks); 3 (50\%) had late preterm deliveries (>34 weeks) and no term delivery.

\section{Table 4: Delivery outcome.}

\begin{tabular}{|lll|}
\hline Maturity & No. of pregnant women $(\mathrm{n}=100)$ & $\%$ \\
\hline Preterm & 12 & 12 \\
\hline Full term & 88 & 88 \\
\hline Total & 100 & 100 \\
\hline
\end{tabular}

In group $\mathrm{A}$, the incidence was $14 \%$ low birth weight; while in group B it was $17 \%$ and in group C it was $83 \%$. Group A all delivered at term and no baby required NICU admission (Table 7).

Table 5: Patients distribution according to reduction in cervical length.

\begin{tabular}{|lll|}
\hline Reduction in cervical length $(\mathrm{cm})$ & $\begin{array}{l}\text { No. of } \\
\text { patient }\end{array}$ & $\%$ \\
\hline Group A $(<0.5 \mathrm{~cm})$ & 28 & 28 \\
\hline Group B $(0.5-1 \mathrm{~cm})$ & 66 & 66 \\
\hline Group C $(>1 \mathrm{~cm})$ & 6 & 6 \\
\hline Total & 100 & 100 \\
\hline
\end{tabular}

Table 6: Patients distribution according to gestational age.

\begin{tabular}{|lllllll|}
\hline $\begin{array}{l}\text { Gestational } \\
\text { age at } \\
\text { delivery }\end{array}$ & $\begin{array}{l}\text { Group A } \\
(\mathbf{n}=28)\end{array}$ & $\begin{array}{l}\text { Group B } \\
(\mathrm{n}=66)\end{array}$ & $\begin{array}{l}\text { Group } \\
\mathrm{C}(\mathrm{n}=6)\end{array}$ \\
$\begin{array}{l}\text { Early preterm } \\
\text { deliveries }(\leq \\
34 \text { weeks) }\end{array}$ & 0 & $0 \%$ & 2 & $3 \%$ & 3 & $50 \%$ \\
$\begin{array}{l}\text { Late preterm } \\
\text { deliveries (>34 } \\
\text { weeks) }\end{array}$ & 0 & $0 \%$ & 4 & $6 \%$ & 3 & $50 \%$ \\
$\begin{array}{l}\text { Term } \\
\text { Gestation }(>37 \\
\text { weeks) }\end{array}$ & 28 & $100 \%$ & 60 & $91 \%$ & 0 & $0 \%$ \\
\hline
\end{tabular}

Table 7: Patients distribution according to birth weight.

\begin{tabular}{llllll|}
$\begin{array}{l}\text { Birth } \\
\text { weight } \\
\text { (kg) }\end{array}$ & Group A & Group B & Group C \\
\hline$<2.5$ & 4 & $14 \%$ & 11 & $17 \%$ & $583 \%$ \\
\hline$\geq 2.5$ & 24 & $86 \%$ & 55 & $83 \%$ & $117 \%$ \\
\hline
\end{tabular}

Table 8 shows diagnostic indices relating to cervical length at 11-14 weeks of gestation cut off value was 3.85 $\mathrm{cm}$ was significant for prediction of preterm labour, but cervical length at 20-22 weeks of gestation cut off value was $2.75 \mathrm{~cm}$ which is extremely significant for preterm labour.

Table 8: Diagnostic indices.

\begin{tabular}{|lllllll|}
\hline Test & Cut off value & Sensitivity & Specificity & PPV & NPV & P value \\
\hline Cervical length at $11-14$ weeks & $3.85 \mathrm{~cm}$ & $66.67 \%$ & $61.36 \%$ & $19.05 \%$ & $93.10 \%$ & 0.03 \\
\hline Cervical length at $20-22$ weeks & $2.75 \mathrm{~cm}$ & $75 \%$ & $100 \%$ & $100 \%$ & $96.70 \%$ & $<0.00001$ \\
\hline Reduction in cx length & $>0.6 \mathrm{~cm}$ & $66.67 \%$ & $87.5 \%$ & $42.11 \%$ & $95.06 \%$ & $<0.00001$ \\
\hline
\end{tabular}

In this study above table shows reduction in cervical length between 11-14 weeks to 20-22 weeks of gestation in prediction of preterm delivery. At the cut-off value of reduction in cervical length between 11-14 weeks and 2022 weeks of gestation of $>0.6 \mathrm{~cm}$, sensitivity was $66.67 \%$, specificity was $87.5 \%$, PPV was $42.11 \%$, NPV was $95.06 \%$, and $\mathrm{p}$ value was $<0.00001$ (extremely significant).

\section{DISCUSSION}

Cervical length measured by endovaginal ultrasound to predict preterm birth was first noted by Andersen et al. ${ }^{10}$

My study was undertaken to assess cervical length by transvaginal ultrasonography during routine NT scan at 11-14weeks and anomaly scan between 20-22 weeks of gestation in 100 booked pregnant women attending the outpatient department of obstetrics, DYP Hospital, Kolhapur meeting the inclusion criteria and were followed up till delivery for pregnancy outcome such as time, and mode of delivery, birth weight etc.

In this study majority of subjects belonged to the age group of 21-25 years, i.e. $53 \%$. In a similar study done by Kore S Jet al majority of women were in the age group of 20-30 years. ${ }^{11}$ Mean age of the subjects studied was 23years. The mean age of similar study done by Leslie A. Moroz et al was 23 years as well. ${ }^{12}$ The median maternal age for the women involved in a similar study by M.H.B. Carvalho et al was 26.2 years. ${ }^{1}$ Minimum age in the study group was 18 years and maximum age was 33 years. The second largest group, i.e. $33 \%$ of the women belonged to the age group of 18-20 years. It was also observed that 
the highest incidence of preterm delivery was in age group 21-25 years i.e. $58.4 \%$, followed by incidence in age group of $18-20$ years i.e. $41.6 \%$ and age $\geq 25$ years all were delivered at term gestation. Relation of age on preterm delivery was significant.

In this study, pregnant women got their scans done between 11-14 weeks and 20-22 weeks of gestation. As recommended the cervical length scan should be performed between11-14weeks with NT scan and 22-24 weeks as part of the anomaly scan. ${ }^{13}$

In this study cervical length at 11-14 weeks, in majority of the patients was between $3.6 \mathrm{~cm}$ to $4 \mathrm{~cm}$. Mean cervical length in the population studied was $3.94 \mathrm{~cm}$. In this study minimum, cervical length measured was $3.0 \mathrm{~cm}$ and maximum cervical length measured was $5.0 \mathrm{~cm}$. Cervical length at 20-22 weeks in same patients, in majority of the patients was between $3.1 \mathrm{~cm}$ to $3.5 \mathrm{~cm}$. Mean cervical length in the population studied was $3.37 \mathrm{~cm}$. In this study, minimum cervical length measured was $2.2 \mathrm{~cm}$ and maximum $4.5 \mathrm{~cm}$. In a similar study by $\mathrm{P}$. Arora et al mean cervical length was $3.2 \mathrm{~cm}$ with minimum measurement of $2.1 \mathrm{~cm}$ and maximum measurement of $4.4 \mathrm{~cm} .{ }^{14}$ In similar studies by Jay D. Iams et al and Hebbar $\mathrm{S}$ et al the mean cervical length was $3.5 \mathrm{~cm} .{ }^{14,9} \mathrm{In}$ my study, majority i.e. $88 \%$ delivered full term between $37-40$ weeks, $9 \%$ delivered moderate to late preterm in $>32-36$ weeks, $3 \%$ delivered early preterm between $28-32$ weeks.

In my study $94.7 \%$ of pregnant women set into spontaneous labour, whereas in $5.3 \%$ of the cases, induction of labour was done for various reasons. Among the subjects studied only $3 \%$ had prelabour rupture of membranes, whereas in $97 \%$ membranes ruptured in the process of labour. In this study, 62\% delivered through vaginal route, whereas $36 \%$ had to undergo caesarean section for varied indications. In $2 \%$ of the cases outlet forceps were used. None of the patients in this study had any complications during delivery. In my study $88 \%$ delivered after 37 weeks of gestation, whereas preterm birth was seen in $12 \%$. This is near to the national average preterm birth rate of India according to Lancet study, which is $13 \%$ of the total births. In my study majority of the babies i.e. $63 \%$ had their birth weights between $2.5 \mathrm{~kg}$ to $3.5 \mathrm{~kg}$. Mean birth weight in our study group was $2.7 \mathrm{~kg}$, which is close to our national average birth weight of $2.8 \mathrm{~kg}$. About $32 \%$ of the babies born had low birth weight between $1.5-2.5 \mathrm{~kg}$, whereas $3 \%$ had very low birth weight of $<1.5 \mathrm{~kg}$ attributing mainly to preterm birth. Birth weight of $3.5-4.5 \mathrm{~kg}$ was seen in $2 \%$ of the babies. In this study, APGAR score at 1 st minute was $<7$ in $10 \%$ of the babies, all were preterm births. In this study $16 \%$ of the babies required immediate NICU admission mostly for preterm care and for respiratory distress. Whereas $84 \%$ of the babies were shifted to mother side after birth. $1 \%$ mortality in this study. In this study, among those who delivered extreme to early preterm, i.e. $<32$ weeks of gestation, $100 \%$ had $>1 \mathrm{~cm}$ cervical length reduction from 11-14weeks to 20-22 weeks gestation through TVS. Among those who delivered moderate to late preterm, i.e. between 32-36 weeks of gestation, $40 \%$ had $>1 \mathrm{~cm}$ cervical length reduction from 11-14weeks to 20-22 weeks gestation through TVS. $60 \%$ had $0.5-1 \mathrm{~cm}$ cervical length reduction from 11-14weeks to 20-22 weeks gestation through TVS. Among those with cervical length of $<0.5 \mathrm{~cm}$, all were term delivery. Among those with cervical length reduction from 11-14 weeks to 20-22 weeks gestation of $0.5-1 \mathrm{~cm}$ preterm delivery occurred in $9 \%$ of women, whereas $91 \%$ delivered full term.

Therefore, a cut-off value of $>0.6 \mathrm{~cm}$ cervical length reduction between 11-14 weeks and 20-22 weeks gestation is better predictor of preterm delivery. In our study, when cervical length difference cut-off value $>0.6$ $\mathrm{cm}$ was applied for predicting preterm delivery, sensitivity was $66.67 \%$, specificity was $87.5 \%$, PPV was $42.11 \%$, NPV was 95.05. In this study, cervical length with cut-off point $>0.6 \mathrm{~cm}$ predicted preterm labour with $\mathrm{P}$-value of $<0.00001$ indicating strong statistical significance.

\section{CONCLUSION}

Our findings confirm those of previous studies that have found an inverse relation between the length of the cervix, as measured by transvaginal ultrasonography during pregnancy, and the frequency of preterm delivery. We found that the cervical length measured at 11-14 weeks and 20-22 weeks gestation was decreased in asymptomatic women with single to $\mathrm{n}$ pregnancies was useful for identifying patients at increased risk for preterm delivery.

Mean value of cervical length in pregnant women at 1114 weeks was $3.94 \mathrm{~cm}$ and 20-22 weeks of gestation in our study was $3.38 \mathrm{~cm}$, there is reduction in cervical length as the pregnancy advances. There is a definite correlation between short cervical length and rate of reduction in cervical length from 1 st trimester to 2 nd trimester with occurrence of preterm delivery.

Our data suggests that the length of the cervixis an in direct indicator of its competence and should be seen as a continuous rather than a dichotomous variable. The length of the cervix is directly correlated with the duration of pregnancy: the shorter the cervix, the greater the likelihood of preterm delivery.

Considering the magnitude of preterm labour, cost of management of preterm babies and morbidity-mortality associated with it, transvaginal ultrasonography of the cervix during routine NT scan and anomaly scan has emerged as a safe, acceptable and a cost-effective test to assess risk of preterm delivery. The predictive value can be further enhanced by calculating cervical index Correlation with increased levels of fibronectin can increase the predictive value of this method. 
Funding: No funding sources

Conflict of interest: None declared

Ethical approval: The study was approved by the Institutional Ethics Committee

\section{REFERENCES}

1. Carvalho MH, Bittar RE, Brizot ML, Maganha PP, Borges da Fonsec ES, Zugaib M. Cervical length at 11-14 weeks' and 22-24 weeks' gestation evaluated by transvaginal sonography, and gestational age at delivery. Ultrasound Obstet Gynecol. 2003;21:135-9.

2. McCormick MC. The contribution of low birth weight to infant mortality and childhood morbidity. N Engl J Med. 1985;312:82-90.

3. Bulletin of the World Health Organization; 2010;88:31-38.

4. Iams JD, Goldenberg RL, Meis PJ. The length of the cervix and the risk of spontaneous premature delivery. National Institute of Child Health and Human Development Maternal Fetal Medicine Unit Network. N Engl J Med. 1996;334:567-72 .

5. Elena $\mathrm{G}$, prediction of spontaneous preterm delivery by endocervical length at 11 to 13 weeks. Prenatal Diagnosis Special Issue: 1st Trimester Screening and Diagnosis. 2011;31(1):84-9.

6. Meir YJ, D'Ottavio G. Does cervical length at 13-15 weeks' gestation predict preterm delivery in an unselected population? Ultrasound Obstet Gynecol. 2003;21:128-34.

7. Skentou CA, Royston P, Yu CK, Nicolaides KH. Prediction of patient-specific risk of early preterm delivery using maternal history and sonographic measurement of cervical length: a population-based prospective study. Ultrasound Obstet Gynecol. 2006;27:362-7.
8. Kagan KO, To M, Tsoi E, Nicolaides KH. Preterm birth: the value of sonographic cervical length measurement. BJOG. 2006;113:52-6.

9. Hebbar S, Samjhana K. Role of mid-trimester transvaginal cervical ultrasound in prediction of preterm delivery. Med J Malaysia. 2006;61(3):30711.

10. Andersen HF, Nugent CE, Wanty SD, Hayashi RH. Prediction of risk for preterm delivery by ultrasonographic measurement of cervical length. Am J Obstet Gynecol. 1990;163(3):859-67.

11. Kore SJ, Parikh MP, Lakhotia, Kulkarni, Ambiye VR. Prediction of risk of preterm delivery by cervical assessment by transvaginal ultrasonography. J Obstet Gynecol India. 2009;59(2):131-5.

12. Moroz LA, Simhan HN. Rate of sonographic cervical shortening and the risk of spontaneous preterm birth. Am J Obstet Gynecol. 2012;206:234:1- 5 .

13. Celik E, M, Gajewska K, Smith GC, Nicolaides KH. Cervical length and obstetric history predict spontaneous preterm birth: development and validation of a model to provide individualized risk assessment. Ultrasound Obstet Gynecol. 2008;31(5):549-54.

14. Arora P, Maitra NK, Agarwal S. Cervical length measurement by transvaginal ultrasound at 20-24 weeks gestation and the timing and mode of delivery. J South Asian Feder Obst Gynae. 2012;4(1):22-4.

Cite this article as: Wadhawan UT, Shah NP, Patil AN. Prediction of preterm labour by cervical length. Int J Reprod Contracept Obstet Gynecol 2017;6:2978-82. 